OPEN ACCESS

Edited by:

Kara Filbey,

University of Manchester,

United Kingdom

Reviewed by:

Matthew Ross Hepworth

University of Manchester,

United Kingdom

Caspar Ohnmacht,

Helmholtz Zentrum

München, Germany

*Correspondence:

R. Lee Reinhardt reinhardt|@NJHealth.org

Specialty section:

This article was submitted to Microbial Immunology,

a section of the journal

Frontiers in Immunology

Received: 22 April 2020

Accepted: 16 June 2020

Published: 23 July 2020

Citation:

Miller MM and Reinhardt RL (2020)

The Heterogeneity, Origins, and Impact of Migratory ilLC2 Cells in

Anti-helminth Immunity.

Front. Immunol. 11:1594.

doi: 10.3389/fimmu.2020.01594

\section{The Heterogeneity, Origins, and Impact of Migratory ilLC2 Cells in Anti-helminth Immunity}

\author{
Mindy M. Miller ${ }^{1}$ and R. Lee Reinhardt ${ }^{1,2 *}$ \\ ${ }^{1}$ Department of Biomedical Research, National Jewish Health, Denver, CO, United States, ${ }^{2}$ Department of Immunology and \\ Microbiology, University of Colorado-Anschutz Medical, Aurora, CO, United States
}

Soil-transmitted helminths represent a major global health burden with infections and infection-related comorbidities causing significant reductions in the quality of life for individuals living in endemic areas. Repeated infections and chronic colonization by these large extracellular worms in mammals led to the evolution of type-2 immunity characterized by the production of the type-2 cytokines interleukin (IL)-4, IL-5, and IL-13. Although a number of adaptive and innate immune cells produce type-2 cytokines, a key cellular source in the context of helminth infection is group 2 innate lymphoid cells (ILC2s). ILC2s promote mucosal barrier homeostasis, integrity, and repair by rapidly responding to epithelial cues in mucosal tissues. Though tissue-resident ILC2s (nILC2s) have been studied in detail over the last decade, considerably less is known with regard to a subset of inflammatory ILC2s (ilLC2s) that migrate to the lungs of mice early after Nippostrongylus brasiliensis infection and are potent early producers of type-2 cytokines. This review will discuss the relationship and differences between nILC2s and ilLC2s that establish their unique roles in anti-helminth immunity. We have placed particular emphasis on studies investigating ilLC2 origin, function, and their potential long-term contribution to tissue-resident ILC2 reservoirs in settings of helminth infection.

Keywords: ilLC2, nILC2, ILC2, helminth, Nippostrongylus brasiliensis, IL-4, IL-13, type-2 immunity

\section{INTRODUCTION}

\section{Global Health Burden of Soil-Transmitted Helminths}

Soil-transmitted helminths include roundworms (Ascaris lumbricoides), whipworms (Trichuris trichiura) and hookworms (Necator americanus; Ancylostoma duodenale) together accounting for infections in at least 1.4 billion people currently, with half of the world's population remaining at risk (1-3). Hookworm transmission is initiated when fertilized eggs are excreted in the feces of infected hosts and hatch in the environment to release infectious larvae. When bare skin is exposed to fecal-contaminated soil, hookworm larvae penetrate the skin, enter the circulation of the host, and migrate to the lungs. Here they enter the parenchyma via pulmonary alveolar capillaries, differentiate and move into pulmonary airspaces, ascend the pharynx, and are swallowed. Larvae eventually take residence in the lumen of the small intestine where they mature into adults and lay eggs. The exception to this lifecycle is the hookworm Anclostoma duodenale, which can be transmitted through the direct ingestion of larvae instead of epithelial penetration. 
While mortality due to STH is concerning, the massive clinical burden associated with helminths manifests from the comorbidities related to anemia, abdominal pain, diarrhea, dehydration, and physical and cognitive growth retardation (4-6). It is estimated that combined STH infection contributes to 5-14 million disability-adjusted life years (DALYs) which disproportionately affects low-income economies already stressed with unmet health care needs $(3,7,8)$. However, even this is likely an underestimation of the overall burden associated with STH infections (9). One DALY equates to the loss of 1 year of "healthy" life over the lifetime of an individual. Although reports of infection rates and DALYs vary, hookworms alone are estimated to infect 400 million individuals and are responsible for 3.2 million DALYs $(1,7)$. This is concerning in particular for school-aged children as hookworm infection has long been associated with reduced cognitive function and academic performance (10-13). Moreover, mothers infected with helminths even a single time during pregnancy may give birth to infants with impaired cognitive and gross motor function (14). Unfortunately, this early-life impairment could lead individuals on a trajectory toward lower productivity and earning capacity when reaching adulthood (15). These comorbidities are compounded by nutrition deficits associated with high helminth burdens. Chronic and repeated helminth colonization has been described as the "world's most important nutrition problem" (16).

Preventative measures have proven highly successful in limiting helminth infections among industrialized nations. This may be best demonstrated by the reduction in the incidence in Necator americanus infections within the southern United States following the Rockefeller Sanitary Commissions' influence in implementing better hygiene practices and access to anthelmintics starting in the early 1900s (17). As a result of these practices, hookworm infection in the United States was effectively eliminated (18). A similar effect was observed during the industrialization of Japan (18). However, in developing nations and more rural regions of the world where basic sanitary needs-such as running water and sewage treatment plants-are lacking and where access to drugs is limited, such preventative measures have been less successful $(3,19,20)$. This is despite the continued goal of the World Health Organization to eliminate STH infections as a public health concern (21). The majority of the WHO's approach has been based on mass chemotherapeutic approaches that would provide regular treatment to $75 \%$ of school age children living in regions endemic to helminth infections. In support of such an approach, several pharmaceutical agents exist to eliminate STH infections, the most common being benzimidazoles which kill the parasite through preventing microtubule polymerization. Although anthelmintic drugs have proven effective at eliminating current infections, they are not preventative and must be re-administered for each subsequent infection (6). As such, repeated treatments have been deemed ineffective in many of the low-socioeconomic communities due to costs associated with frequent clinic visits and the logistics of providing routine access to drugs within key endemic populations. For example, 39 countries do not yet meet the $75 \%$ treatment goal, and when preschool-aged children are included in the target demographic, $<50 \%$ of children are receiving the expected chemotherapy regimen $(3,22)$. Even among children receiving treatment, the high rates of reinfection and inconsistent access to drugs has made the goal of helminth eradication by this approach difficult to achieve $(5,23-25)$. Furthermore, there is increasing concern that sporadic chemotherapeutic interventions will increase the incidence of drug-resistance, particularly in nematodes (20, 26, 27). Additional concern lies in side effects associated with these drugs. Even though most anthelmintics are well-tolerated, side effects include gastrointestinal discomfort and the high doses required to treat echinococcal liver cysts have been associated with hair loss, bone marrow suppression, and hepatic injury (28). Thus, while advances in anthelmintic drugs are likely to continue to make a positive impact on the global burden of helminthrelated morbidity, there is a continued need for additional pharmaceutical agents and/or vaccines tailored toward the safe prevention/elimination of infections. Novel approaches to limit infection and worm burden would benefit from a more complete understanding of the immune response to helminths.

\section{Type-2 Inflammation and Anti-helminth Immunity}

The majority of animal studies assessing immunity to soiltransmitted helminths utilize either the murine hookworm Nippostrongylus brasiliensis, which mimics the lifecycle of the human pathogen Necator americanus, or the fecal-oral, intestinal roundworm model of Heligomosomoides polygyrus. Whether assessing the lung or the intestine in these models, a characteristic wound healing or tissue repair response is observed and is referred to as type-2 immunity (29). Although type- 2 immune responses are often observed in the context of allergic asthma, this form of immunity likely evolved to protect the host from comorbidities associated with chronic or repeated helminth exposure and is ideally suited to promoting parasite clearance and tissue repair (30-32). While the relationship between anti-helminth immunity and allergic disease is complex, evidence suggests that despite invoking similar type- 2 inflammatory processes, helminth infection does not always exacerbate allergic inflammation (33). In fact, recent literature shows that there is likely an early-life window that can be exploited to influence an individual's susceptibility to chronic diseases including asthma in later life (34). Such helminthmediated suppression of allergic immunity would support the observation that individuals living in rural areas endemic to helminth infection develop allergic disease in a smaller percentage of the population than do individuals living in more industrialized communities that are devoid of parasitic helminths (35-38). Empirical studies also support this conclusion (3942). Mice infected with various parasitic helminths, including Heligmosomoides polygyrus, Nippostrongylys brasiliensis, and Litomosoides sigmodontis, show reduced allergic lung disease when sensitized and challenged with allergens. Together, the evidence suggests that mammals evolved suppressive mechanisms that work in concert with type- 2 inflammation to tolerate and/or clear helminth infection. These mechanisms 
are likely advantageous to individuals by limiting the damage induced by repeated worm infection and colonization. As such, allergy and asthma may be more recent manifestations of type-2 inflammation in hosts that lack the natural exposure to these parasitic worms $(43,44)$. In this case, the "poised" type-2 immunity designed to tolerate helminths now responds inappropriately to innocuous allergens. This represents an important variation of the hygiene hypothesis (45-47).

Type-2 immunity is orchestrated through the production of the type-2 cytokines interleukin (IL)-4, IL-5, and IL-13 (48). These three cytokines have both unique and redundant roles in anti-helminth immunity. IL- 4 produced by follicular helper $\mathrm{T}$ cells in the context of helminth infection is critical for the production of immunoglobulin (Ig) $\mathrm{E}$ and high-affinity IgG1 (49-51). Although the crosslinking of IgE receptors on basophils and mast cells appears limited in primary $N$. brasiliensis infection, IgE-mediated activation of basophils is likely more extensive during secondary helminth responses $(52,53)$. In addition, IL-4 from basophils and eosinophils also promotes type-2 inflammation at the site of infection/colonization (54-56). Although IL-13 likely plays a role within pathogenic IgE response to allergens, it does not appear to affect the production of IgE during acute helminth infection $(57,58)$. Instead, IL-13 primarily acts on the epithelium at mucosal barriers. Specifically, IL-13 can enhance goblet and tuft cell hyperplasia, increase mucus production, accelerate epithelial cell turnover, and aid in smooth muscle contractility in settings of type- 2 inflammation $(57,59-$ 62). IL-13 appears to be dominant to IL-4 in these processes primarily due to two factors. First, while the IL-4 receptor found on goblet cells and smooth muscle cells can bind both IL-4 and IL13, it has higher affinity for IL-13 $(63,64)$. Second, while IL-4 is the dominant cytokine produced in lymphoid tissues during helminth infection, IL-13 appears to be more restricted to immune cells residing in mucosal tissues $(50,57)$. This increases the availability of IL-13 to modulate goblet cell hyperplasia and smooth muscle contractility. Furthermore, type- 2 cytokines can induce the production of downstream epithelial cytokines that are equally important in pathogen clearance. For example. IL4/IL-13-induced goblet cells produce the cytokine RELM-beta which can directly impair helminth fecundity and survival (65, 66). Unlike IL-4 and IL-13-which can compensate to promote characteristic type- 2 hallmarks $(67,68)$ - IL-5 appears to have a more specific role in type- 2 responses confined primarily to the mobilization of eosinophils from the bone marrow to enhance wound healing and further increase IL-4 levels as they are the most prevalent IL-4-competent population at the peak of the $N$. brasiliensis response (56). Moreover, eosinophils likely play a role in direct killing of infectious larvae, particularly after reinfection (69).

The biologic importance of IL-4, IL-5, and IL-13 in antihelminth immunity is best evidenced by changes in helminth worm clearance among cytokine-deficient mice. In support of IL-13 being the dominant type- 2 cytokine in promotion of worm expulsion, IL-13-deficient mice displayed delayed helminth clearance compared to IL-4-deficient animals (70, 71). However, mice lacking both IL-4 and IL-13 exhibited a greater deficit in worm clearance than that observed in IL-13 single knockouts, indicating synergy of these type-2 cytokines in the context of $N$. brasiliensis infection (72). This result was phenocopied in mice where IL-13-producing cells were deleted upon diphtheria toxin administration (57). Importantly, IL4/IL-5/IL-13-triple knockout mice show exceptionally delayed $N$. brasiliensis clearance (73). Together these cytokines perform three key functions important to anti-helminth immunity. First, they promote the mobilization of innate and adaptive type- 2 immune cells to sites of helminth infection and mucosal barrier damage. Second, they work synergistically and independently to induce the weep (mucus production) and sweep (smooth muscle contractility) response to mechanically expel the worms. Lastly, these cytokines are involved in the repair of damaged epithelium that results during helminth migration and colonization. Although IL-4, IL-5, and IL-13 are responsible for the majority of type-2 immune hallmarks observed during helminth infection, IL-9 has been described to have additional effects on worm clearance $(73,74)$.

A systematic assessment of the immune response throughout $N$. brasiliensis infection highlights the lung as an essential location of immune orchestration (Figure 1). While the first encounter of the pathogen occurs at the epithelium when larvae penetrate the skin and enter circulation, this event is relatively quick $(0-6 \mathrm{~h})$. Nonetheless, there will be some local irritation and epithelial damage that recruits neutrophils and eosinophils to the tissue. The most extensive tissue damage occurs after the parasite has traveled through the vasculature and invades the lung parenchyma via alveolar capillaries in the airspace between 18 and $72 \mathrm{~h}$ after infection (31). This leads to hemorrhage and acute lung injury, partly mediated through neutrophil accumulation and activation (31). Epithelial cell-derived trefoil factor 2 controls helminth induced hemorrhagic lung injury and is necessary for IL-33 production (75). Resulting epithelial injury releases IL-25 and IL-33, both of which prompt type- 2 cytokine production first from type-2 innate lymphoid cells (ILC2s) and, later, Th2 cells. After entry into the lung parenchyma, L3 larvae undergo maturation to the L4 stage and migrate to the airways where they travel up the pharynx and are swallowed. Upon entering the upper small intestine, L4 larvae latch onto the epithelium to feed, mature into L5 larvae, and produce eggs which are excreted in feces. Similar to the lung, damaged intestinal epithelium produces IL-25 and IL-33 further promoting the weep and sweep response. In mice with intact immune systems, the helminth is cleared within $8-10$ days after infection. This is also when adaptive Th2 cells and eosinophils predominate as the major type-2 producing immune populations in the lung (56). Of note, the pathology observed in the lung after day 7 of infection by $N$. brasiliensis strongly resembles that of human asthmatic airways $(32,76)$.

As discussed above, tissue alarmins IL-25 and IL-33 are essential to ILC2 function in anti-helminth immunity. While damaged/dying epithelium represent important sources of these alarmins during the initial stages of helminth infection, many additional cellular sources have been described which likely impact ILC2 cells later in the response. For example, IL-33 is produced by adventitial stromal cells during helminth infection whereas type II pneumocytes and white adipose tissue-resident 


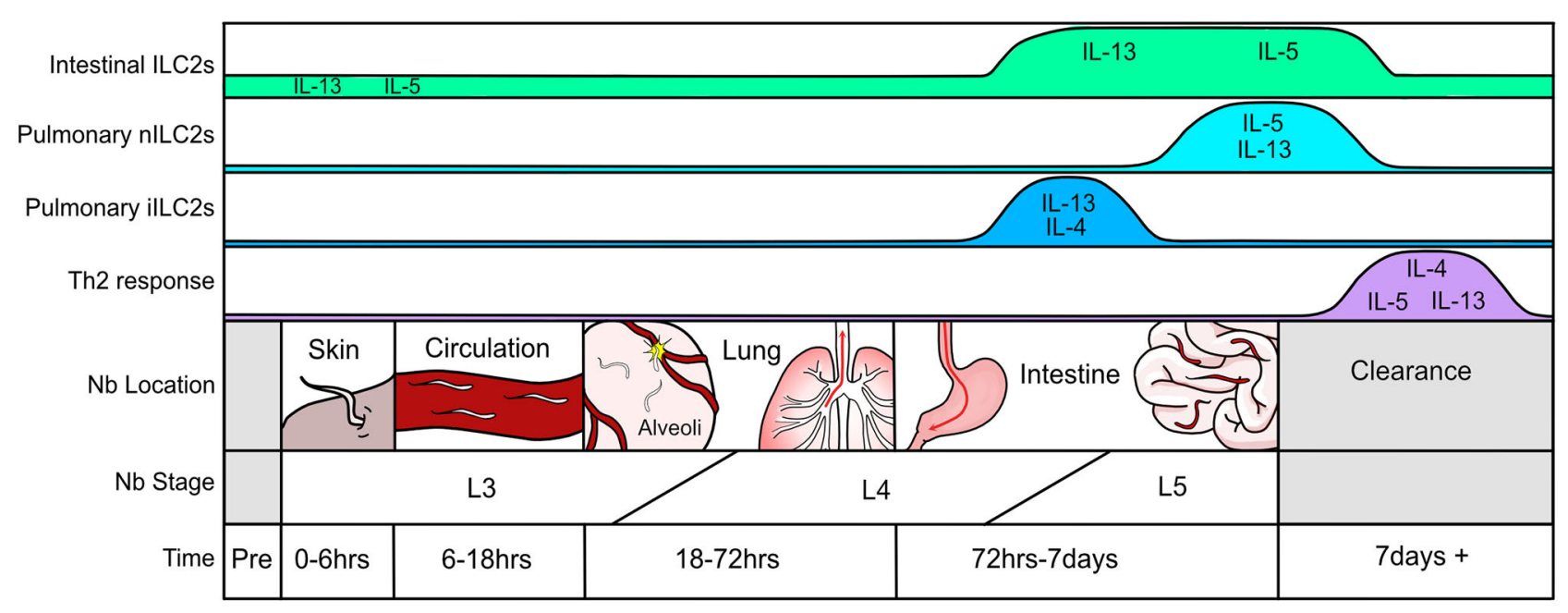

FIGURE 1 | Timeline of the immune response to Nippostrongylus brasiliensis infection.

stromal stem cells produce IL-33 in other settings of type-2 inflammation (77-80). Similarly, IL-25 has been shown to be produced by many type- 2 immune cells including Th2 cells, mast cells, alveolar macrophages, eosinophils and basophilsall of which may contribute to ILC2 activation (81-84). These cellular sources are in addition to more recently described IL25-producing intestinal tuft cells and chemosensory brush cells found in the lung which play key roles in ILC2 homeostasis and expansion in settings of type-2 inflammation (85-89).

As initial responders of tissue damage caused by helminth infection, ILC2s serve a unique role in orchestrating the type-2 response that is required for worm clearance and epithelial repair. A detailed understanding of the immune response, especially that of ILC2s, is requisite to address the public health needs of treating helminth infections and preventing associated comorbidities.

\section{GROUP 2 INNATE LYMPHOID CELLS}

\section{ILC2s and Anti-helminth Immunity Discovery of ILC2s}

In 2001, a rare non-B/non-T (NBNT) cell population that responded to IL-25 and produced type- 2 cytokines was described in settings of allergic inflammation (81). These cells resembled $\mathrm{CD}^{+} \mathrm{T}$ cells in many ways but lacked a known antigen receptor. It was proposed that this population worked in concert with Th2 cells to promote type- 2 immune hallmarks. This IL-25responsive NBNT population was later observed in the context of helminth infection where it was described as a prominent producer of type- 2 cytokines during infection (90). However, it was not until almost a decade after their initial discovery that this NBNT population became part of the collective consciousness of researchers studying type-2 immunity (91-93). These studies showed that this innate lymphoid population rapidly produces IL-13 in response to the tissue alarmins IL-33 and IL-25. It was later shown that innate lymphoid cells could respond to the tissue alarmin TSLP to produce IL-5 and IL-13, but this appears to occur mainly in the skin leaving the impact of TSLP in other stages of helminth infection less clear $(94,95)$. While early studies used different names to describe innate lymphoid cells, consensus was reached in 2013 to identify them as group 2 innate lymphoid cells (ILC2s) based on their production of type2 cytokines, distinguishing them from other innate lymphocytes classified as group 1 and group 3 ILCs (96). Over the last 10 years, significant advances have been made in elucidating the unique biological roles for all three subsets of ILCs, but ILC2s appear uniquely suited to respond to helminth infections and aid in the promotion of a protective type- 2 immune response (97).

While wild-type mice can clear $N$. brasiliensis within 8-10 days of infection, mice lacking $\mathrm{T}$ cells and $\mathrm{B}$ cells remain colonized with worms after several weeks of infection (59). Although this highlights the essential nature of Th2 cells in productive worm clearance, additional importance of ILC2s in anti-helminth immunity is 2 -fold. Not only do these cells contribute to parasite expulsion by orchestrating early cytokine production via their sensing of tissue alarmins, but ILC2s are also involved in mucosal barrier homeostasis and the reparative response after helminthmediated tissue damage. The potential contribution of ILC2s in parasite clearance can first be seen in a study from 2006 prior to the discovery of ILC2s where IL-25-deficient mice which exhibited impaired worm clearance relative to wild-type mice, despite the presence of T cells (90). Looking back at this study, ILC2s can be directly implicated in this process as RAG-deficient mice (lacking $\mathrm{B}$ and $\mathrm{T}$ cells) given recombinant IL-25 cleared $N$. brasiliensis within 5 days of infection (90). These results were replicated in the first studies defining ILC2s where it was shown that IL-33 could also induce rapid helminth clearance, linking both IL-25 and IL-33 as early activators of ILC2s $(92,93)$. Indeed, transfer of ILC2s back into mice deficient in both $\mathrm{T}$ cells and ILCs (Rag2 $2^{-/-} I l 2 r \gamma^{-/-}$mice) was sufficient to promote worm clearance $(91,93)$. It is important to note that this rapid 
clearance following alarmin administration was dependent on type-2 cytokines and particularly IL-13-expressing ILC2 cells $(57,90,92,93)$. In addition to their role in primary infection, ILC2 cells in concert with memory Th2 cells effectively limit worm burden and larval-induced lung damage upon secondary infection implicating a broader yet less defined role for ILC2 cells after repeated helminth exposure (98).

\section{ILC2s in Barrier Homeostasis}

In addition to their role in helminth expulsion, ILC2s in the small intestine serve an important function in barrier homeostasis via recognition of IL-25 made by chemosensory tuft cells residing in the epithelium (85-87). At steady state, dietary polysaccharides and metabolites bind directly to receptors on epithelial tuft cells and regulate their production of IL- $25(86,99,100)$. ILC2s in the intestinal lamina propria sense the tuft cell-derived IL-25. This maintains a low level of IL-13 production by intestinal resident ILC2s which then cues stem cells to differentiate into relatively low numbers of goblet and tuft cells (101). Upon colonization of the intestine by helminths such as $N$. brasiliensis and $H$. polygyrus, tuft cell expansion is increased $(85-87,102)$. Tuft cells act as early sentinels of intestinal infection by recognizing metabolites generated by pathogens that breech the mucosal barrier and produce substantially more IL-25 leading to increased ILC2derived IL-13. This feed-forward circuit leads to the characteristic goblet and tuft cell hyperplasia observed in settings of type- 2 inflammation. The increase in tuft cell-derived IL-25 as well as other alarmins generated as a result of tissue damage and cell death work in concert to promote type-2 immunity.

\section{ILC2 Function}

As discussed above, the lifecycle of the hookworm in the host causes a substantial amount of tissue damage and ILC2s provide an essential function in wound healing. This is particularly evident at two stages of infection in the lung: first when the infectious L3 larvae enter the lung parenchyma via the capillary endothelium, and then during the second stage of damage as L4 larvae migrate in search of the alveolar airspace. This is grossly observed in the lungs of mice 3 days after $N$. brasiliensis infection as punctate foci of damage and diffuse pulmonary hemorrhage. As sensors of epithelial damage, ILC2s are poised to respond quickly to such injury. It is clear that one of the major roles of tissue-resident ILC2s is to promote the mobilization of eosinophils in the bone marrow, which is enacted via their capacity to produce large amounts of IL-5 on a per cell basis (103). This corresponds to the characteristic eosinophilia that peaks around 9-12 days post-infection (73, 104). By day 12 in the response to $N$. brasiliensis, ILC2s are making IL-9 which is thought to autocrine amplify and be essential for tissue repair and restoration of lung function (105). Although IL-9 has a much lesser role in helminth immunity as compared to IL-4 and IL-13, ILC2-derived IL9 likely enhances the production of IL-5 and IL-13, making this cytokine a potential modulator of the severity of type- 2 inflammation $(73,74,106)$. Also contributing to tissue repair is ILC2-derived epidermal growth factor (EGF)-like molecule amphiregulin (107). Though less is known about ILC2-generated amphiregulin in tissue repair within helminth infection, it is likely to be similar to that of other models with mucosal tissue damage. Such examples include the role of amphiregulin in modulation of dextran sulfate induced intestinal inflammation and influenza infection where ILC2-derived amphiregulin was critical in restoring barrier integrity and mediating airway remodeling $(108,109)$. A role for amphiregulin produced by ILC2 cells has also been observed in atopic dermatitis (110). In these models IL-33 induces the expression of amphiregulin in ILC2 cells, thereby promoting tissue repair. While the activity of ILC2-derived amphiregulin in tissue repair has not been studied in helminth models, it is likely to play a role as its expression is increased 12 days after $N$. brasiliensis infection (105). More recently, it was suggested that amphiregulin-producing ILC2s are a subset distinct from IL-5/IL-13-producing ILC2s (111). This study assessed pulmonary ILC2s at steady state in neonatal mice and used gene expression profiles to separate ILC2s into either Klrg1/Il5/Il13- or Icos/amphiregulin-expressing subsets. Future studies that identify and explore tissue-resident ILC2 heterogeneity may be able to assign differing roles for these subsets in anti-helminth immunity and other tissue-damaging infections or diseases.

\section{Inflammatory ilLC2s and Anti-helminth Immunity Phenotype}

Until recently, ILC2s were largely considered to be a homogenous population. This was in contrast to ILC1s and ILC3s which consisted of distinct populations within each subset. However, evidence began to emerge that suggested heterogeneity within ILC2s. Early experiments using Il1rl1- (IL-33 receptor) and Il17rb- (IL-25 receptor) deficient mice revealed that IL-33 and IL25 were not equal in their ability to promote type- 2 hallmarks or helminth clearance (92). A theme became apparent in which IL-33 was the dominant alarmin associated with ILC2 activation, and IL-25 mediated a more selective role (112-114). Transcriptomics analyses later revealed distinct gene signatures in both mouse and human ILC2s further supporting that this innate lymphoid population was more diverse than previously believed (115-117).

Despite the suggested heterogeneity among ILC2s, the majority of studies to date were unable to assign distinct roles to different ILC2 subsets. The inability to reliably identify unique ILC2 subsets in vivo likely masked their separate but important contributions in anti-helminth immunity. However, this changed when a subset of ILC2s that could be distinguished by their differential responsiveness to an epithelial alarmin was characterized in the context of N. brasiliensis infection (118). This study identified a population of IL-25-responsive ILC2s that accumulated in the lungs of mice 5 days post- $N$. brasiliensis infection or in mice that were given intraperitoneal IL-25. These cells, which were coined inflammatory ILC2s or iILC2s, were not found in the lung at steady state and disappeared within 12 days after $N$. brasiliensis infection. This is in contrast to the everpresent, tissue-resident, IL-33-responsive ILC2 subset, termed natural ILC2s or nILC2s. This study also demonstrated that 
iILC2s phenotypically express high KLRG1 and low CD90 levels, whereas nILC2s have low KLRG1 but high CD90 expression. In some ways, iILC2s appear similar to IL-25-elicited MPP type2 cells as both populations are $\mathrm{Lin}^{-} \mathrm{c}-\mathrm{Kit}^{+}$and respond to the same alarmin. However, MPP ${ }^{\text {type } 2}$ cells are characterized by the lack of CD90 and IL-7R $\alpha$ expression which distinguishes them from ilLC2s $(114,118,119)$.

As their functional determinants imply, iILC2s which preferentially respond to IL-25 express more IL-25 receptor, whereas IL-33-responsive nILC2s display more IL-33 receptor on their surface $(118,120)$. Together, these markers allowed the consistent delineation between ilLC2 and nILC2 cells (Figure 2). In addition to these cell surface markers, arginase 1 (Arg1) was later identified as a robust discriminator of the two subsets. It was previously thought that all ILC2s and their progenitors express this enzyme (121-123). However, while nILC2s display high Arg1 reporter expression using $\operatorname{Arg} 1^{\text {YFP }}$ reporter mice, iILC2s express very little allowing for distinction between subsets (120). Interestingly, Arg1 expression in human pulmonary ILC2s obtained from individuals with chronic lung disease also appears to define two separate subsets. Human IL-33 receptor ${ }^{+}$ILC2s displayed high Arg1 levels but not CRTH2 ${ }^{+}$ILC2s (123). Whether these two subsets in humans are related to nILC2s and iILC2s in mice is not yet known. Future investigations that delineate these ILC2 subsets using distinct phenotypic markers are likely to provide a more comprehensive understanding of the specific contributions allotted to these and potentially other ILC2 subsets.

\section{ilLC2 Function in Helminth Infection}

The impact of illC2 cells in anti-helminth immunity is demonstrated in mice lacking Il25 or the IL-25 receptor Il17rb -which fail to specifically activate iILC2s-and display impaired $N$. brasiliensis expulsion $(90,92)$. This is complemented by experiments showing exogenous IL-25 administration is able to mediate $N$. brasiliensis clearance in mice lacking $\mathrm{T}$ cells but not in those lacking both $\mathrm{T}$ cells and ILCs $(90,93)$. Moreover, mice deficient for the AP-1 transcription factor BATF fail to generate pulmonary iILC2s and display impaired IL-25mediated helminth clearance (40). Importantly, BATF deficiency had no impact on IL-33-mediated worm clearance or nILC2 numbers. Together, these data indicate that the IL-25-responsive iILC2 subset aids in mobilizing the immune response for rapid pathogen clearance and acts distinctly from tissue-resident IL-33responsive subsets particularly in settings where IL-25 dominates the early alarmin response to infection.

It is logical that differences in cytokine production would exist between the ILC2 subsets. Tissue-resident pulmonary nILC2s, which are active at the peak of the response (days 8-10) to $N$. brasiliensis, are highly skewed toward IL-13 and IL-5 production

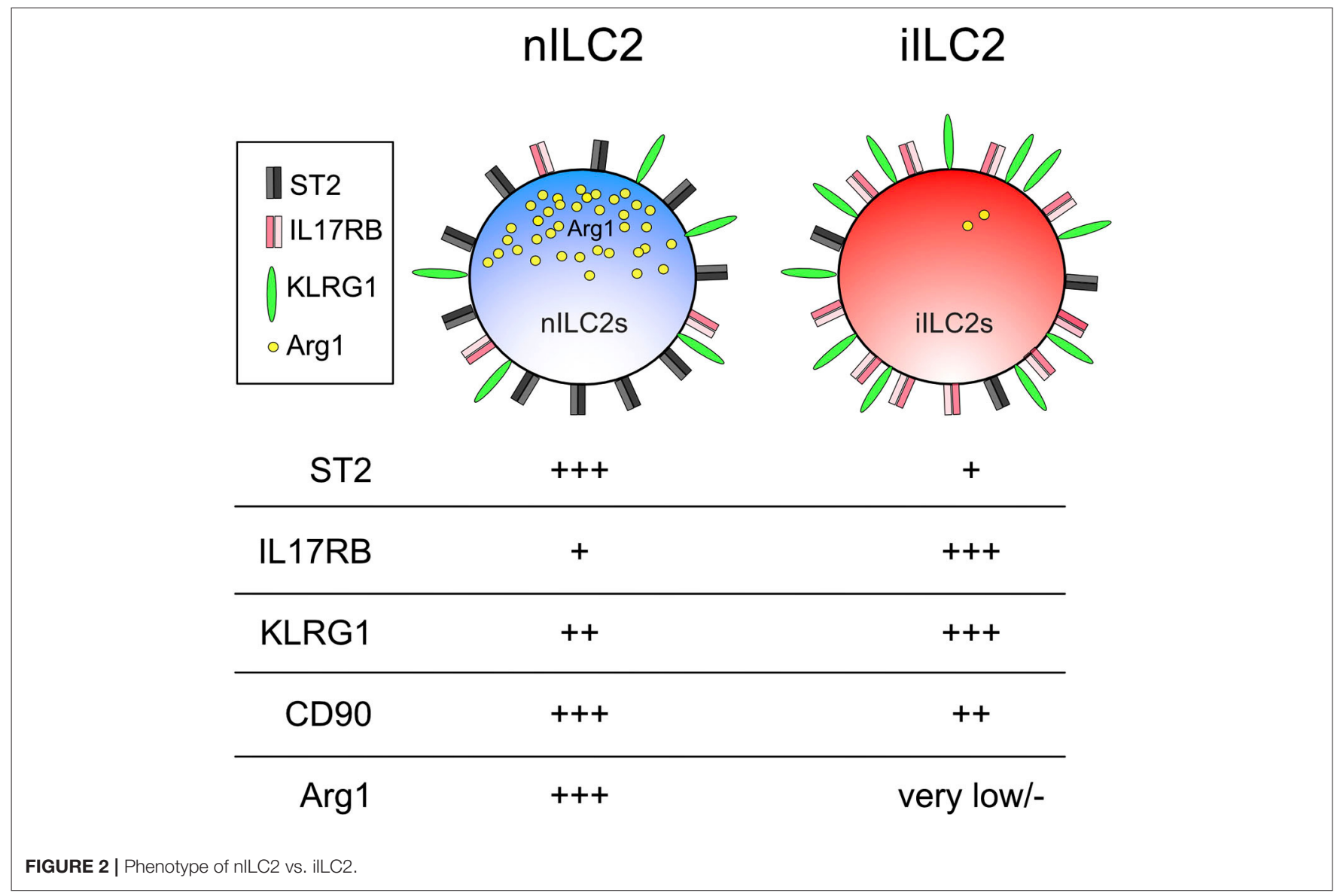


with minimal IL-4 production $(56,57)$. Similarly, in response to intraperitoneal IL-25, there is a reported preference among iILC2s to produce IL-13 and little IL-4 as determined in 4C13R mice, which express AmCyan and DsRed-DR under Il4 and Il13 regulatory elements, respectively (118). However, in the context of $N$. brasiliensis infection, ilLC2s make IL-4 in addition to IL13 at 5 days post-infection (120). This study utilized the IL4 $4^{4 g e t}$, $I L 4^{K N 2}, I L 13^{\text {Yetcre } 13}$, and IL13 ${ }^{\text {Smart13 }}$ reporter mice which can be used as a readout of mRNA (IL4 $4^{4 \text { get }}$ and $I L 13^{\text {Yetcre } 13}$ ) or protein $\left(I L 4^{K N 2}\right.$ and $I L 13^{\text {Smart13 }}$ ) production $(57,93,124,125)$. Further differences between cytokine capabilities can be parsed out by assessing the temporal response to infection. At day 5 post- $N$. brasiliensis infection, cytokine production by ILC2s demonstrates that only the iILC2 compartment, and not nILC2s, are making type- 2 cytokines (120). This is relatively early in the response and precedes cytokine production by tissue-resident IL-33-responsive nILC2s $(126,127)$.

While IL-13 is the major ILC2-derived cytokine in the intestine, IL-4 can promote goblet and tuft cell differentiation in organoid cultures similar to that observed after administration of recombinant IL-13, suggesting there may be a role for ILC2-derived IL-4 in maintaining intestinal barrier homeostasis (85-87, 128). Indeed, IL-4 production by intestinal ILC2s has been reported in response to Heligmosomoides polygyrus (129). Although this is an indication that ILC2-derived IL-4 in the intestine after $H$. polygyrus infection may play a role similar to that of early, migratory iILC2 cells in the lung after $N$. brasiliensis infection, some care should be noted. This study used IL-4-transcript reporter mice (IL4 ${ }^{4 g e t}$ ), which have been shown to mark ILC2 populations that are not readily producing IL-4 protein $(56,57,93)$. Further complicating this conclusion, the prior study assessed cytokine protein only ex vivo after restimulation with phorbol 12-myristate 13-acetate (PMA) and ionomycin, a stimulus that drives translation of all cytokine-competent loci and may not reflect true in vivo cytokine production (56). Thus, it remains somewhat unclear if these intestinal ILC2 cells are actively producing IL-4 protein in vivo. If IL-4 protein production is confirmed, it is of interest to assess whether this IL-4 production reflects either: tissue-specific differences among nILC2 cells in the lung and intestine; helminth-specific differences related to infection by $N$. brasiliensis or $H$. polygyrus; or reflects an intestinal iILC2 population that maintains IL-4 protein production throughout the course of $H$. polygyrus infection.

Polyfunctionality and potential plasticity of ilLC2s has also been described. Intraperitoneal IL-25 administration generated iILC2s that express elevated levels of Roryt compared to nILC2s, though not as high as that of ILC3s from the small intestine (118). Furthermore, iILC2s were capable of producing IL-17 when stimulated with PMA and ionomycin, indicating potential plasticity between iILC2s and ILC3-like cells $(118,130)$. The polyfunctionality of iILC2s to produce IL-17 along with type- 2 cytokines also sets them apart from nILC2s. This may indicate critical functional differences between the two subsets as ilLC2s contribute to protection from the IL-17-sensitive pathogen Candida albicans (118). It may also reflect an inherent plasticity of iILC2 cells compared to nILC2 cells. Indeed, nILC2 cells require tissue specific signals in order to undergo their ultimate maturation (131). In support of ILC2/ILC3 plasticity, the lysine methyltransferase G9a could act as a switch to promote ILC3 and repress ILC2 commitment (132). Whether this epigenetic switch is active specifically in ilLC2s or their progenitors relative to nILC2 cells is not clear. There is also some evidence to support ILC2/ILC3 plasticity in human ILC2s. Studies have shown two separate populations of human ILC2s delineated on c-Kit expression, as opposed to alarmin-receptor expression observed in mice. In these analyses, the c-Kit-positive subset exhibits similarities to ILC3s and is able to produce IL-17 (133, 134). The extent that ILC2 or ILC2 progenitors can regulate ILC3 responses will be an important area of future research as we try to better understand the importance of ILCs in barrier defense and repair. Future studies investigating the relative contribution of iILC2 compared to ILC3 populations would be of great interest toward defining their role in IL-17-mediated immunity.

\section{Fate of ilLC2s}

The fate of iILC2s remains unclear. As ilLC2s are only transiently found in the lung, it could be argued that they are relatively unimportant in the grand scheme of pulmonary immunity. However, the rapid disappearance of these cells has been attributed to their ability to convert to either the IL-33-responsive nILC2 population or IL-17-producing ILC3s (118). This study demonstrated that sorted ilLC2s cultured under various conditions increased IL-33 receptor expression, a phenotype similar to that of nILC2s. In vivo, iILC2s transferred into congenic hosts upregulated the IL-33 receptor, again indicating a potential conversion to nILC2s (118). Furthermore, the fold increase of nILC2 cells after helminth infection was significantly reduced in $I l 17 r b^{-/-}$mice, which lack iILC2s, indicating a strong contribution of iILC2s to the nILC2 pool (118). However, studies using a tamoxifen-inducible fate mapping system that labels ILC2s concluded that repopulation and maintenance of the lung nILC2 pool after helminth infection was the result of self-renewal by tissue-resident nILC2s and not the addition of "de novo" generated ILC2s, which would include iILC2s $(135,136)$. Specifically, this system used an Arg1 ${ }^{R F P-C r e E R T 2}$ R26R-YFP mouse. In this mouse, all Arg1expressing cells, including ILC2 precursors, were labeled with RFP and CreERT2. Administration of tamoxifen allowed Cremediated excision of the stop codon in the Rosa locus allowing permanent expression of YFP to fate map ILC2 populations throughout development. The majority of cells appeared to be self-renewed (i.e., retained YFP expression), which is consistent with prior literature suggesting self-renewal for both ILC1 and nILC2 populations $(137,138)$. Despite this, the fate mapping system identified that 12 days after a single $N$. brasiliensis infection, roughly $10-15 \%$ of nILC2s consisted of non-labeled cells $(135,136)$. This suggests that up to $15 \%$ of the tissueresident pool may have been generated from converted iILC2s after barrier damage. Based on the knowledge that ilLC2s are absent at 12 days post- $N$. brasiliensis infection, this time point is consistent with when ilLC2s would have already converted to nILC2s. Thus, it is possible that although self-renewal is the predominant source of nILC2 homeostasis at rest, converting 
iILC2 cells may contribute substantially to the overall tissueresident ILC2 pool over a lifetime of infections. Whether iILC2s are truly multipotent progenitors is not yet established, but these initial findings may indicate more plasticity among ILCs than previously appreciated as was recently reviewed (139).

Regarding experiments to assess conversion, it should be noted that while delineation of iILC2 and nILC2 populations based on KLRG1 expression works well for $N$. brasiliensis infection, there are other situations which lead nILC2s to increase KLRG1 levels. In particular, daily IL-33-administration for 4 days, as well as repopulation of irradiated mice with bone marrow, leads nILC2s to upregulate KLRG1 levels and drop CD90 slightly so that their phenotype resembles an intermediate between nILC2s and iILC2s (120). Moreover, these changes may be strain- and context-specific as Alternaria alternata exposure or IL-33 administration over 2 weeks lead to upregulation of CD90 on ILC2s isolated from bronchoalveolar lavage fluid in $\mathrm{C} 57 \mathrm{BL} / 6$ but not BALB/c mice (140). In contrast, ILC2s isolated from lung tissue displayed downregulated CD90 only in BALB/c mice. Thus, using CD90 or KLRG1 expression levels to assess conversion may be confounded by inherent changes of these markers due to time, activation status, and tissue-specific signals. Further studies using more stringent markers of ILC2 subsets, such as Arg1, to determine conversion would strengthen the argument that iILC2s contribute substantially to the immune landscape of the lung.

\section{Origin of ilLC2s}

It is not currently well understood where pulmonary iILC2s originate. As discussed, ILC2s have been considered tissueresident cells that are replenished by self-renewal within their tissue of residence $(131,137)$. Using the fate mapping system described above where ILC2s are permanently labeled at various timepoints throughout development, it was demonstrated that the majority of lung-resident ILC2s in adulthood were derived during the postnatal period with some contribution of prenatalderived cells and little influx of cells seeded during adulthood (135). This data explains the prior evidence that pulmonary type 2 immune cells - including ILC2s-arise in the lung shortly after birth (141-143). After N. brasiliensis infection, there was a statistically significant increase in non-fate mapped pulmonary ILC2s indicating that ILC2s do not arise solely from self-renewal during inflammation but may be recruited to the lung from other sites $(135,136)$. This is supported by studies where the appearance of ilLC2s in the lung depends on S1P-dependent migration $(120,136,144,145)$. In these studies, administration of the S1P-receptor agonist FTY720 prevented the appearance of iILC2s in the lung after IL-25 administration or helminth infection, indicating the requirement for ilLC2s to egress from lymphoid organs into circulation. Mucosal sites such as the small intestine and lung as well as sites of hematopoiesis like the bone marrow are all candidate reservoirs (Figure 3). Furthermore, evidence that $\mathrm{c}-\mathrm{Kit}^{+}$ILC precursors are also found in human blood, tonsils, and lung and can give rise to all ILC subsets indicates the potential for multiple sites of origin (146).

The most convincing source of migratory iILC2s in the lung has been the small intestine $(136,144,145)$. In a comprehensive

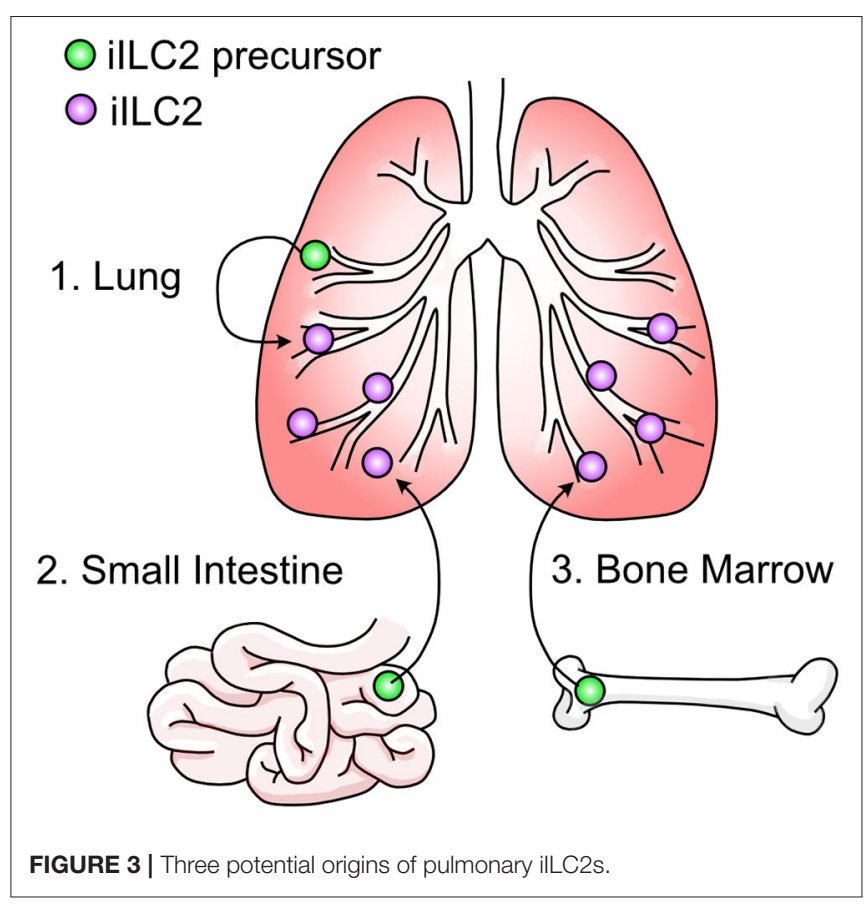

experiment to determine the source of ilLC2s, total ILC2s were isolated from the lung, small intestine, and precursors from the bone marrow. When these cells were transferred into congenic hosts, pulmonary ilLC2s arose in mice that received small intestine ILC2s (144). However, it should be noted that mice given ILC2 precursors from the bone marrow-but not the lung-also gave rise to pulmonary iILC2s, although to a lesser extent than those from intestine. It has been further demonstrated that IL-25-responsive iILC2s in the lung resemble small intestine ILC2s by transcriptional profile and phenotype $(136,144,145,147)$. Recently, a population of ILC2s resembling pulmonary iILC2s were found in mesenteric lymph nodes after $N$. brasiliensis infection which were absent in IL-33-deficient mice (147). Although migration of intestinal ILC2s to the mesenteric lymph nodes has been described previously (144), this study suggests that IL-33 binds to ST2 ${ }^{+}$nILC2s in the small intestine and through induction of the gene Tph1, generates ST2- ilLC2s. This mechanism would be consistent with the idea that pulmonary iILC2 cells originating in the intestine lose their nILC2 phenotype prior to their arrival in the lung. We previously proposed that such a conversion from an nILC2 phenotype toward an iILC2 phenotype must occur if pulmonary iILC2s originate in the intestine based on the uniform expression of the nILC2 marker arginase-1 within intestinal ILC2 cells and its absence among pulmonary iILC2 cells (120). However, because pulmonary and mesenteric iILC2 populations have not been directly compared, care should be taken in overinterpreting these conclusions at least as they relate to an intestinal origin for pulmonary iILC2 populations. In this regard, a few outstanding questions remain unresolved. First, addition of IL-25 and not IL33 drives the appearance of pulmonary iILC2 cells suggesting that IL-33 may differentially impact mesenteric iILC2 and pulmonary 
iILC2 $(118,147)$. Second, while ST2 expression is abundant on nILC2 cells residing in the lung, few intestinal nILC2 cells express the IL-33 receptor at steady state (except in conditions where IL33 expression in the intestine is forced by a transgene) $(120,147)$. How IL-33 is modulating intestinal ILC2s or whether specific $\mathrm{ST}_{2}{ }^{+}$subsets are responsible for the generation of mesenteric iILC2s will be of interest. Third, while the mesenteric lymph node iILC2 population is observed 7 days post $N$. brasiliensis infection, pulmonary iILC2s are more transient and largely absent by this timepoint in the lung (118). Fourth, while iILC2s and nILC2s in the mesenteric lymph node or intestine express similar levels of KLRG1, iILC2s in the lung express noticeably more KLRG1 than pulmonary nILC2s. This discrepancy, along with that of arginase-1 expression as noted above, suggests that phenotypes of ILC2s likely differ depending on their tissue of residence making extrapolations based on phenotype with regard to cell origin difficult $(118,120,136,144,145$, 147). That said, there is evidence supporting that an intestinal origin for pulmonary iILC2 extends beyond studies with $\mathrm{N}$. brasiliensis. Mice infected with the parasitic nematode Trichinella spiralis, which infects only the intestinal tract, demonstrated mobilization of iILC2s to the lung (145). These mice also displayed increased pulmonary mucin production due to iILC2derived IL-13, indicating that an intestinal infection alone can mobilize iILC2s to the lung and drive mucosal immunity at distal sites. At present, conclusive demonstration of an intestinal origin for pulmonary iILC2s and its impact on iILC2 biology in the lung as well as investigation of whether other tissue sources outside the intestine contribute to pulmonary iILC2 cells await further experimentation.

In order for pulmonary iILC2s to originate from a lung source and undergo S1P-mediated migration, these cells would have to egress from the lung into circulation and then return back to the lung. This does not seem outside the realm of possibility, given the high degree of nILC2 motility and migration to perivascular spaces upon IL-33 treatment (148). In support, pulmonary ILC2s reside in adventitial niches allowing these cells the proximity to readily sample the vasculature (78). This scenario would also require iILC2s to be generated from nILC2s or a lungresident precursor. Although in vivo support is limited, one study describes the requirement of Notch signaling for the generation of iILC2s, and when nILC2s were cultured on Notch ligandexpressing cells they adopted an iILC2 phenotype and gained the ability to produce IL-17 (130). Additionally, IL-18R $\alpha^{+}$ILC precursors have recently been reported in the murine lung that are capable of giving rise to nILC2s (111). It would be of interest to assess whether this lung tissue-resident precursor subset can also differentiate into iILC2s during helminth infection.

As the primary site of hematopoiesis in adults, the bone marrow also serves as a reservoir for ILC2 precursors (ILC2Ps). ILC2Ps have been defined as $\mathrm{Lin}^{-} \mathrm{Sca}{ }^{\text {hi }} \mathrm{GATA}^{\mathrm{hi}} \mathrm{CD} 90^{+} \mathrm{CD} 127^{+} \mathrm{Id} 2^{+} \mathrm{IL}_{2} \mathrm{r}^{+}{ }^{+}$(149). However, common ILC precursors and ILC2Ps in the bone marrow express gut homing molecules such as $\alpha 4 \beta 7$ and CCR 9 making it difficult to acertain if such markers observed on lung iILC2 reflect an intestinal or bone marrow migrant (150). Further, even though lung ILC2s are seeded into their tissues of residence during pre- and postnatal development (135), there is evidence that IL-33 drives the egress of ILC2s from bone marrow progenitors (151). It is possible that other inflammatory signals may release iILC2 cells from a bone marrow progenitor, although this has not yet been assessed. Technical advances such as the generation of polychromic transcription factor reporter mice have been used to identify both uncommited ILC precursors and ILC2-specific precursors in the bone marrow as well as ILC2 precursors in the small intestine lamina propria (152). This would serve as an interesting model to identify the progenitor population as well as anatomical location that can give rise to iILC2s.

\section{DISCUSSION}

\section{Current Gaps in Knowledge and Future Directions}

While the role of ilLC2s in helminth infection is clear, there have been few studies demonstrating their appearance in other infection or disease models. As early mediators of type- 2 immunity, it is interesting to speculate that iILC2s are involved in allergic responses. However, two recent studies have failed to demonstrate their recruitment to the lung using the house dust mite (HDM) model of allergic inflammation $(120,140)$. It is unknown whether IL-25 production is the main driver in iILC2 lung accumulation in the HDM setting or perhaps there is insufficient IL-25 production in the HDM model-and other models of type-2 immunity-to promote the expansion and migration of iILC2s to the lung. Disparities in pulmonary iILC2 accumulation between allergic and helminth models could also reflect differential involvement and location of IL-25-producing intestinal tuft cells and pulmonary brush cells. With this in mind, if iILC2s are first induced by intraperitoneal injections of IL-25 and then artificially transferred into T cell- and ILC2deficient mice, they are able to mediate allergic responses upon HDM challenge (130). This data may indicate that while certain allergic responses do not normally recruit these cells to the lung, if iILC2 cells are already present in the lung (i.e., due to a helminth infection) at the time of allergen exposure, these cells may yet exacerbate type- 2 inflammation. Whether such a mechanism explains why some individuals relocating to the United States from helminth-endemic regions show increased type-2 inflammation upon allergen exposure is not known (153). This is interesting to consider in context of mounting evidence that suggests helminth colonization suppresses the onset and severity of allergic disease $(40,154,155)$. Although helminths are the focus here, other infections or insults that generate IL-25 and recruit iILC2s to the lung may similarly exacerbate allergic outcomes upon allergen exposure. Such models need to be explored to indicate iILC2 involvement.

While the use of reporter mouse systems have greatly impacted our overall understanding of ILC2 biology and provided unique opportunities to track the fate and function of these rare cells in vivo, it is necessary to acknowledge the inherent pitfalls associated with such systems. Reporter systems are often designed to enhance detection. This leads to 
alterations in gene regulation as well as mRNA and protein stability that may not reflect true biology of the wildtype gene. Aside from reporter "leakiness" where fluorescence or surface molecules may falsely indicate gene expression, there may also be contextual nuances that are missed. Gene expression and regulation is complex and sensitive to cell type, location, immune environment, and many other factors, each of which may lead to over-interpretation of results if not rigorously evaluated. As such, while innovative reporter models are likely to continue to be an important part of an investigators tool kit, complementation with unbiased approaches is becoming standard. An excellent example of this is the increasing use of single cell RNA sequencing to explore ILC2 biology. We expect platforms designed to interrogate the transcriptomics, genomics, proteomics, and metabolomics of ILC2 cells at the single cell level, when paired with traditional methods, will be critical to our collective understanding of ILC2s in settings of helminth infection.

Most importantly, how iILC2s contribute to the short- and long-term pulmonary landscape will be of great clinical interest. Eventually it will be necessary to detect pulmonary ilLC2s in helminth-infected humans. If iILC2s convert to nILC2s and are retained in the lung, there would be significant contribution of

\section{REFERENCES}

1. Pullan RL, Smith JL, Jasrasaria R, Brooker SJ. Global numbers of infection and disease burden of soil transmitted helminth infections in 2010. Parasit Vectors. (2014) 7:37. doi: 10.1186/1756-3305-7-37

2. Weatherhead JE, Hotez PJ, Mejia R. The global state of helminth control and elimination in children. Pediatr Clin North Am. (2017) 64:867-77. doi: $10.1016 /$ j.pcl.2017.03.005

3. Freeman MC, Akogun O, Belizario VJr, Brooker SJ, Gyorkos TW, Imtiaz $\mathrm{R}$, et al. Challenges and opportunities for control and elimination of soiltransmitted helminth infection beyond 2020. PLoS Negl Trop Dis. (2019) 13:e0007201. doi: 10.1371/journal.pntd.0007201

4. Miller TA. Hookworm infection in man. Adv Parasitol. (1979) 17:315-84. doi: 10.1016/S0065-308X(08)60552-7

5. Brooker S, Bethony J, Hotez PJ. Human hookworm infection in the 21st century. Adv Parasitol. (2004) 58:197-288. doi: 10.1016/S0065-308X(04)58004-1

6. Bethony J, Brooker S, Albonico M, Geiger SM, Loukas A, Diemert D, et al. Soil-transmitted helminth infections: ascariasis, trichuriasis, and hookworm. Lancet. (2006) 367:1521-32. doi: 10.1016/S0140-6736(06)68653-4

7. Murray CJ, Vos T, Lozano R, Naghavi M, Flaxman AD, Michaud C, et al. Disability-adjusted life years. (DALYs) for 291 diseases and injuries in 21 regions, 1990-2010: a systematic analysis for the Global Burden of Disease Study 2010. Lancet. (2012) 380:2197-223. doi: 10.1016/S0140-6736(12)61689-4

8. Hotez PJ, Strych U, Lustigman S, Bottazzi ME. Human anthelminthic vaccines: rationale and challenges. Vaccine. (2016) 34:3549-55. doi: 10.1016/j.vaccine.2016.03.112

9. Hotez PJ, Brindley PJ, Bethony JM, King CH, Pearce EJ, Jacobson J. Helminth infections: the great neglected tropical diseases. J Clin Investig. (2008) 118:1311-21. doi: 10.1172/JCI34261

10. Waite JHN. A study of the effects of hookworm infection upon the mental development of north queensland school children. Med J Aust. (1919) 1:1-7. doi: 10.5694/j.1326-5377.1919.tb29570.x

11. Sakti H, Nokes C, Hertanto WS, Hendratno S, Hall A, Bundy DA, et al. Evidence for an association between hookworm infection and cognitive these former ilLC2s to the lung-resident population over the course of a lifetime as each infection could potentially contribute to the pulmonary ILC2 pool. In this scenario, de novo ILC2 populations like iILC2 cells, rather than self-renewing, tissueresident populations, would likely become the predominant ILC2 population in mucosal sites. Such studies would expand our understanding of basic lung immunity, while continuing to inform the development of novel therapeutic strategies aimed at reducing the global health burden of STHs.

\section{AUTHOR CONTRIBUTIONS}

MM and RR wrote the review. Both authors contributed to the article and approved the submitted version.

\section{FUNDING}

This study was supported by R01AI119004 (RR) and Windsweep Farm Fellowship (MM).

\section{ACKNOWLEDGMENTS}

We thank Ivy K. Brown for critical review of the manuscript. function in Indonesian school children. Trop Med Int Health. (1999) 4:32234. doi: 10.1046/j.1365-3156.1999.00410.x

12. Jardim-Botelho A, Raff S, Rodrigues Rde A, Hoffman HJ, Diemert DJ, Correa-Oliveira R, et al. Hookworm, Ascaris lumbricoides infection and polyparasitism associated with poor cognitive performance in Brazilian schoolchildren. Trop Med Int Health. (2008) 13:994-1004. doi: $10.1111 / j .1365-3156.2008 .02103 . x$

13. Kuong K, Fiorentino M, Perignon M, Chamnan C, Berger J, Sinuon M, et al. Cognitive performance and iron status are negatively associated with hookworm infection in cambodian schoolchildren. Am J Trop Med Hyg. (2016) 95:856-63. doi: 10.4269/ajtmh.15-0813

14. Mireku MO, Boivin MJ, Davidson LL, Ouedraogo S, Koura GK, Alao MJ, et al. Impact of helminth infection during pregnancy on cognitive and motor functions of one-year-old children. PLoS Negl Trop Dis. (2015) 9:e0003463. doi: 10.1371/journal.pntd.0003463

15. Guyatt H. Do intestinal nematodes affect productivity in adulthood? Parasitol Today. (2000) 16:153-8. doi: 10.1016/S0169-4758(99) 01634-8

16. Hotez PJ, Bundy DA, Beegle K, Brooker S, Drake L, de Silva N, et al. Chapter 24Helminth Infections: Soil-transmitted Helminth Infections and Schistosomiasis. Washington, DC; New York, NY: The International Bank for Reconstruction and Development/The World Bank; Oxford University Press (2006).

17. Ettling J. The Germ of Laziness: Rockefeller Philanthropy and Public Health in the New South. Cambridge, MA: Harvard University Press (1981).

18. Pawłowski ZS, Schad GA, Stott GJ. Hookworm Infection and Anaemia: Approaches to Prevention and Control. Geneva: World Health Organization (1991).

19. Strunz EC, Addiss DG, Stocks ME, Ogden S, Utzinger J, Freeman MC. Water, sanitation, hygiene, and soil-transmitted helminth infection: a systematic review and meta-analysis. PLoS Med. (2014) 11:e1001620. doi: 10.1371/journal.pmed.1001620

20. Campbell SJ, Nery SV, McCarthy JS, Gray DJ, Soares Magalhaes RJ, Clements ACA. A critical appraisal of control strategies for soil-transmitted helminths. Trends Parasitol. (2016) 32:97-107. doi: 10.1016/j.pt.2015. 10.006 
21. WHO. Soil-Transmitted Helminthiases: Eliminating as Public Health Problem Soil-Transmitted Helminthiases in Children: Progress Report 2001-2010 and Strategic Plan 2011-2020. Geneva: World Health Organization (2012).

22. Hotez PJ, Fenwick A, Ray SE, Hay SI, Molyneux DH. "Rapid impact" 10 years after: the first "decade". (2006-2016) of integrated neglected tropical disease control. PLoS Negl Trop Dis. (2018) 12:e0006137. doi: 10.1371/journal.pntd.0006137

23. Albonico M, Smith PG, Ercole E, Hall A, Chwaya HM, Alawi KS, et al. Rate of reinfection with intestinal nematodes after treatment of children with mebendazole or albendazole in a highly endemic area. Trans $R$ Soc Trop Med Hyg. (1995) 89:538-41. doi: 10.1016/0035-9203(95)90101-9

24. Flohr C, Tuyen LN, Lewis S, Minh TT, Campbell J, Britton J, et al. Low efficacy of mebendazole against hookworm in Vietnam: two randomized controlled trials. Am J Trop Med Hyg. (2007) 76:732-6. doi: 10.4269/ajtmh.2007.76.732

25. Cundill B, Alexander N, Bethony JM, Diemert D, Pullan RL, Brooker S. Rates and intensity of re-infection with human helminths after treatment and the influence of individual, household, and environmental factors in a Brazilian community. Parasitology. (2011) 138:1406-16. doi: $10.1017 /$ S0031182011001132

26. De Clercq D, Sacko M, Behnke J, Gilbert F, Dorny P, Vercruysse J. Failure of mebendazole in treatment of human hookworm infections in the southern region of Mali. Am J Trop Med Hyg. (1997) 57:25-30. doi: 10.4269/ajtmh.1997.57.25

27. Jia TW, Melville S, Utzinger J, King CH, Zhou XN. Soil-transmitted helminth reinfection after drug treatment: a systematic review and meta-analysis. PLoS Negl Trop Dis. (2012) 6:e1621. doi: 10.1371/journal.pntd.0001621

28. Pearson RD, Weller PF, Guerrant RL. CHAPTER 12 - chemotherapy of parasitic diseases. In: Guerrant RL, Walker DH, Weller PF, editors. Tropical Infectious Diseases: Principles, Pathogens and Practice. 3rd ed. Edinburgh: WB Saunders (2011). p. 76-94.

29. Gieseck RL III, Wilson MS, Wynn TA. Type 2 immunity in tissue repair and fibrosis. Nat Rev Immunol. (2018) 18:62-76. doi: 10.1038/nri.2017.90

30. Allen JE, Maizels RM. Diversity and dialogue in immunity to helminths. Nat Rev Immunol. (2011) 11:375-88. doi: 10.1038/nri2992

31. Allen JE, Sutherland TE. Host protective roles of type 2 immunity: parasite killing and tissue repair, flip sides of the same coin. Semin Immunol. (2014) 26:329-40. doi: 10.1016/j.smim.2014.06.003

32. Fahy JV. Type 2 inflammation in asthma-present in most, absent in many. Nat Rev Immunol. (2015) 15:57-65. doi: 10.1038/nri3786

33. Smits HH, Yazdanbakhsh M. Chronic helminth infections modulate allergen-specific immune responses: Protection against development of allergic disorders? Ann Med. (2007) 39:428-39. doi: 10.1080/07853890701436765

34. Round JL, Mazmanian SK. The gut microbiota shapes intestinal immune responses during health and disease. Nat Rev Immunol. (2009) 9:313-23. doi: $10.1038 /$ nri2515

35. Lynch NR, Lopez R, Isturiz G, Tenias-Salazar E. Allergic reactivity and helminthic infection in Amerindians of the Amazon Basin. Int Arch Aller Appl Immunol. (1983) 72:369-72. doi: 10.1159/000234899

36. Nyan OA, Walraven GE, Banya WA, Milligan P, Van Der Sande M, Ceesay $\mathrm{SM}$, et al. Atopy, intestinal helminth infection and total serum IgE in rural and urban adult Gambian communities. Clin Exp Aller. (2001) 31:1672-8. doi: 10.1046/j.1365-2222.2001.00987.x

37. Cooper PJ, Chico ME, Rodrigues LC, Ordonez M, Strachan D, Griffin $\mathrm{GE}$, et al. Reduced risk of atopy among school-age children infected with geohelminth parasites in a rural area of the tropics. J Aller Clin Immunol. (2003) 111:995-1000. doi: 10.1067/mai.2003.1348

38. Smits HH, Hammad H, van Nimwegen M, Soullie T, Willart MA, Lievers E, et al. Protective effect of Schistosoma mansoni infection on allergic airway inflammation depends on the intensity and chronicity of infection. J Aller Clin Immunol. (2007) 120:932-40. doi: 10.1016/j.jaci.2007.06.009

39. Wohlleben G, Trujillo C, Muller J, Ritze Y, Grunewald S, Tatsch U, et al. Helminth infection modulates the development of allergen-induced airway inflammation. Int Immunol. (2004) 16:585-96. doi: 10.1093/intimm/dxh062

40. Wilson MS, Taylor MD, Balic A, Finney CA, Lamb JR, Maizels RM. Suppression of allergic airway inflammation by helminth-induced regulatory T cells. J Exp Med. (2005) 202:1199-212. doi: 10.1084/jem.20042572
41. Dittrich AM, Erbacher A, Specht S, Diesner F, Krokowski M, Avagyan A, et al. Helminth infection with Litomosoides sigmodontis induces regulatory $\mathrm{T}$ cells and inhibits allergic sensitization, airway inflammation, and hyperreactivity in a murine asthma model. J Immunol. (2008) 180:17929. doi: 10.4049/jimmunol.180.3.1792

42. Zaiss MM, Rapin A, Lebon L, Dubey LK, Mosconi I, Sarter K, et al. The intestinal microbiota contributes to the ability of helminths to modulate allergic inflammation. Immunity. (2015) 43:998-1010. doi: 10.1016/j.immuni.2015.09.012

43. Fumagalli M, Pozzoli U, Cagliani R, Comi GP, Riva S, Clerici M, et al. Parasites represent a major selective force for interleukin genes and shape the genetic predisposition to autoimmune conditions. J Exp Med. (2009) 206:1395-408. doi: 10.1084/jem.20082779

44. Barreiro LB, Quintana-Murci L. From evolutionary genetics to human immunology: how selection shapes host defence genes. Nat Rev Genet. (2010) 11:17-30. doi: $10.1038 / \mathrm{nrg} 2698$

45. Strachan DP. Hay fever, hygiene, and household size. BMJ. (1989) 299:125960. doi: 10.1136/bmj.299.6710.1259

46. Wills-Karp M, Santeliz J, Karp CL. The germless theory of allergic disease: revisiting the hygiene hypothesis. Nat Rev Immunol. (2001) 1:69-75. doi: $10.1038 / 35095579$

47. Rook GA. Hygiene hypothesis and autoimmune diseases. Clin Rev Aller Immunol. (2012) 42:5-15. doi: 10.1007/s12016-011-8285-8

48. Bao K, Reinhardt RL. The differential expression of IL-4 and IL13 and its impact on type-2 immunity. Cytokine. (2015) 75:25-37. doi: 10.1016/j.cyto.2015.05.008

49. King IL, Mohrs M. IL-4-producing CD4+ T cells in reactive lymph nodes during helminth infection are T follicular helper cells. J Exp Med. (2009) 206:1001-7. doi: 10.1084/jem.20090313

50. Reinhardt RL, Liang HE, Locksley RM. Cytokine-secreting follicular T cells shape the antibody repertoire. Nat Immunol. (2009) 10:385-93. doi: 10.1038/ni.1715

51. Zaretsky AG, Taylor JJ, King IL, Marshall FA, Mohrs M, Pearce EJ. T follicular helper cells differentiate from Th2 cells in response to helminth antigens. $J$ Exp Med. (2009) 206:991-9. doi: 10.1084/jem.20090303

52. Ohnmacht C, Voehringer D. Basophil effector function and homeostasis during helminth infection. Blood. (2009) 113:2816-25. doi: 10.1182/blood-2008-05-154773

53. Sullivan BM, Liang HE, Bando JK, Wu D, Cheng LE, McKerrow JK, et al. Genetic analysis of basophil function in vivo. Nat Immunol. (2011) 12:52735. doi: 10.1038/ni.2036

54. Coyle AJ, Kohler G, Tsuyuki S, Brombacher F, Kopf M. Eosinophils are not required to induce airway hyperresponsiveness after nematode infection. Eur J Immunol. (1998) 28:2640-7. doi: 10.1002/(SICI)1521-4141(199809)28:09<2640::AID-IMMU2640>3.0. $\mathrm{CO} ; 2-\mathrm{X}$

55. Voehringer D, Shinkai K, Locksley RM. Type 2 immunity reflects orchestrated recruitment of cells committed to IL-4 production. Immunity. (2004) 20:267-77. doi: 10.1016/S1074-7613(04)00026-3

56. O’Brien TF, Bao K, Dell'Aringa M, Ang WX, Abraham S, Reinhardt RL. Cytokine expression by invariant natural killer $\mathrm{T}$ cells is tightly regulated throughout development and settings of type-2 inflammation. Mucosal Immunol. (2016) 9:597-609. doi: 10.1038/mi.2015.78

57. Liang HE, Reinhardt RL, Bando JK, Sullivan BM, Ho IC, Locksley RM. Divergent expression patterns of IL-4 and IL-13 define unique functions in allergic immunity. Nat Immunol. (2012) 13:58-66. doi: 10.1038/ni.2182

58. Gowthaman U, Chen JS, Zhang B, Flynn WF, Lu Y, Song W, et al. Identification of a $\mathrm{T}$ follicular helper cell subset that drives anaphylactic IgE. Science. (2019) 365:eaaw6433. doi: 10.1126/science.aaw6433

59. Barner M, Mohrs M, Brombacher F, Kopf M. Differences between IL-4R alpha-deficient and IL-4-deficient mice reveal a role for IL13 in the regulation of Th2 responses. Curr Biol. (1998) 8:669-72. doi: 10.1016/S0960-9822(98)70256-8

60. Grunig G, Warnock M, Wakil AE, Venkayya R, Brombacher F, Rennick DM, et al. Requirement for IL-13 independently of IL-4 in experimental asthma. Science. (1998) 282:2261-3. doi: 10.1126/science.282.5397.2261

61. Cliffe LJ, Humphreys NE, Lane TE, Potten CS, Booth C, Grencis RK. Accelerated intestinal epithelial cell turnover: a new mechanism of 
parasite expulsion. Science. (2005) 308:1463-5. doi: 10.1126/science.110 8661

62. Hasnain SZ, Evans CM, Roy M, Gallagher AL, Kindrachuk KN, Barron L, et al. Muc5ac: a critical component mediating the rejection of enteric nematodes. J Exp Med. (2011) 208:893-900. doi: 10.1084/jem.20102057

63. Kelly-Welch AE, Hanson EM, Boothby MR, Keegan AD. Interleukin-4 and interleukin-13 signaling connections maps. Science. (2003) 300:1527-8. doi: $10.1126 /$ science. 1085458

64. LaPorte SL, Juo ZS, Vaclavikova J, Colf LA, Qi X, Heller NM, et al. Molecular and structural basis of cytokine receptor pleiotropy in the interleukin-4/13 system. Cell. (2008) 132:259-72. doi: 10.1016/j.cell.2007.12.030

65. Artis D, Wang ML, Keilbaugh SA, He W, Brenes M, Swain GP, et al. RELMbeta/FIZZ2 is a goblet cell-specific immune-effector molecule in the gastrointestinal tract. Proc Natl Acad Sci USA. (2004) 101:13596-600. doi: 10.1073/pnas.0404034101

66. Herbert DR, Yang JQ, Hogan SP, Groschwitz K, Khodoun M, Munitz $\mathrm{A}$, et al. Intestinal epithelial cell secretion of RELM-beta protects against gastrointestinal worm infection. J Exp Med. (2009) 206:2947-57. doi: 10.1084/jem.20091268

67. Corry DB, Folkesson HG, Warnock ML, Erle DJ, Matthay MA, WienerKronish JP, et al. Interleukin 4, but not interleukin 5 or eosinophils, is required in a murine model of acute airway hyperreactivity. J Exp Med. (1996) 183:109-17. doi: 10.1084/jem.183.1.109

68. Rankin JA, Picarella DE, Geba GP, Temann UA, Prasad B, DiCosmo B, et al. Phenotypic and physiologic characterization of transgenic mice expressing interleukin 4 in the lung: lymphocytic and eosinophilic inflammation without airway hyperreactivity. Proc Natl Acad Sci USA. (1996) 93:7821-5. doi: 10.1073/pnas.93.15.7821

69. Patnode ML, Bando JK, Krummel MF, Locksley RM, Rosen SD. Leukotriene B4 amplifies eosinophil accumulation in response to nematodes. J Exp Med. (2014) 211:1281-8. doi: 10.1084/jem.20132336

70. Lawrence RA, Gray CA, Osborne J, Maizels RM. Nippostrongylus brasiliensis: cytokine responses and nematode expulsion in normal and IL-4-deficient mice. Exp Parasitol. (1996) 84:65-73. doi: 10.1006/expr.1996.0090

71. McKenzie GJ, Bancroft A, Grencis RK, McKenzie AN. A distinct role for interleukin-13 in Th2-cell-mediated immune responses. Curr Biol. (1998) 8:339-42. doi: 10.1016/S0960-9822(98)70134-4

72. McKenzie GJ, Fallon PG, Emson CL, Grencis RK, McKenzie AN. Simultaneous disruption of interleukin. (IL)- 4 and IL-13 defines individual roles in Thelper cell type 2-mediated responses. J Exp Med. (1999) 189:156572. doi: $10.1084 /$ jem.189.10.1565

73. Fallon PG, Jolin HE, Smith P, Emson CL, Townsend MJ, Fallon $\mathrm{R}$, et al. IL-4 induces characteristic Th2 responses even in the combined absence of IL-5, IL-9, and IL-13. Immunity. (2002) 17:7-17. doi: 10.1016/S1074-7613(02)00332-1

74. Licona-Limon P, Henao-Mejia J, Temann AU, Gagliani N, LiconaLimon I, Ishigame $\mathrm{H}$, et al. Th9 cells drive host Immunity against gastrointestinal worm infection. Immunity. (2013) 39:744-57. doi: 10.1016/j.immuni.2013.07.020

75. Wills-Karp M, Rani R, Dienger K, Lewkowich I, Fox JG, Perkins C, et al. Trefoil factor 2 rapidly induces interleukin 33 to promote type 2 immunity during allergic asthma and hookworm infection. J Exp Med. (2012) 209:60722. doi: $10.1084 /$ jem. 20110079

76. Chen F, Wu W, Millman A, Craft JF, Chen E, Patel N, et al. Neutrophils prime a long-lived effector macrophage phenotype that mediates accelerated helminth expulsion. Nat Immunol. (2014) 15:938-46. doi: 10.1038/ni.2984

77. Hardman CS, Panova V, McKenzie AN. IL-33 citrine reporter mice reveal the temporal and spatial expression of IL-33 during allergic lung inflammation. Eur J Immunol. (2013) 43:488-98. doi: 10.1002/eji.20124 2863

78. Dahlgren MW, Jones SW, Cautivo KM, Dubinin A, Ortiz-Carpena JF, Farhat S, et al. Adventitial stromal cells define group 2 innate lymphoid cell tissue niches. Immunity. (2019) 50:707-22 e706. doi: 10.1016/j.immuni.2019.02.002

79. Mahlakoiv T, Flamar AL, Johnston LK, Moriyama S, Putzel GG, Bryce PJ, et al. Stromal cells maintain immune cell homeostasis in adipose tissue via production of interleukin-33. Sci Immunol. (2019) 4:eaax0416. doi: 10.1126/sciimmunol.aax0416
80. Rana BMJ, Jou E, Barlow JL, Rodriguez-Rodriguez N, Walker JA, Knox C, et al. A stromal cell niche sustains ILC2-mediated type-2 conditioning in adipose tissue. J Exp Med. (2019) 216:1999-2009. doi: 10.1084/jem.20190689

81. Fort MM, Cheung J, Yen D, Li J, Zurawski SM, Lo S, et al. IL-25 induces IL4, IL-5, and IL-13 and Th2-associated pathologies in vivo. Immunity. (2001) 15:985-95. doi: 10.1016/S1074-7613(01)00243-6

82. Ikeda K, Nakajima H, Suzuki K, Kagami S, Hirose K, Suto A, et al. Mast cells produce interleukin-25 upon Fc epsilon RI-mediated activation. Blood. (2003) 101:3594-6. doi: 10.1182/blood-2002-09-2817

83. Kang CM, Jang AS, Ahn MH, Shin JA, Kim JH, Choi YS, et al. Interleukin-25 and interleukin-13 production by alveolar macrophages in response to particles. Am J Respir Cell Mol Biol. (2005) 33:290-6. doi: $10.1165 / \mathrm{rcmb} .2005-0003 \mathrm{OC}$

84. Wang YH, Angkasekwinai P, Lu N, Voo KS, Arima K, Hanabuchi S, et al. IL-25 augments type 2 immune responses by enhancing the expansion and functions of TSLP-DC-activated Th2 memory cells. J Exp Med. (2007) 204:1837-47. doi: 10.1084/jem.20070406

85. Gerbe F, Sidot E, Smyth DJ, Ohmoto M, Matsumoto I, Dardalhon V, et al. Intestinal epithelial tuft cells initiate type 2 mucosal immunity to helminth parasites. Nature. (2016) 529:226-30. doi: 10.1038/nature16527

86. Howitt MR, Lavoie S, Michaud M, Blum AM, Tran SV, Weinstock JV, et al. Tuft cells, taste-chemosensory cells, orchestrate parasite type 2 immunity in the gut. Science. (2016) 351:1329-33. doi: 10.1126/science.aaf1648

87. von Moltke J, Ji M, Liang HE, Locksley RM. Tuft-cell-derived IL-25 regulates an intestinal ILC2-epithelial response circuit. Nature. (2016) 529:221-5. doi: 10.1038/nature16161

88. Bankova LG, Dwyer DF, Yoshimoto E, Ualiyeva S, McGinty JW, Raff H, et al. The cysteinyl leukotriene 3 receptor regulates expansion of IL-25producing airway brush cells leading to type 2 inflammation. Sci Immunol. (2018) 3:eaat9453. doi: 10.1126/sciimmunol.aat9453

89. Kohanski MA, Workman AD, Patel NN, Hung LY, Shtraks JP, Chen B, et al. Solitary chemosensory cells are a primary epithelial source of IL25 in patients with chronic rhinosinusitis with nasal polyps. J Allergy Clin Immunol. (2018) 142:460-69 e467. doi: 10.1016/j.jaci.2018.03.019

90. Fallon PG, Ballantyne SJ, Mangan NE, Barlow JL, Dasvarma A, Hewett DR, et al. Identification of an interleukin. (IL)-25-dependent cell population that provides IL-4, IL-5, and IL-13 at the onset of helminth expulsion. J Exp Med. (2006) 203:1105-16. doi: 10.1084/jem.20051615

91. Moro K, Yamada T, Tanabe M, Takeuchi T, Ikawa T, Kawamoto $\mathrm{H}$, et al. Innate production of $\mathrm{T}(\mathrm{H}) 2$ cytokines by adipose tissueassociated c-Kit $(+)$ Sca-1(+) lymphoid cells. Nature. (2010) 463:540-4. doi: 10.1038/nature08636

92. Neill DR, Wong SH, Bellosi A, Flynn RJ, Daly M, Langford TK, et al. Nuocytes represent a new innate effector leukocyte that mediates type-2 immunity. Nature. (2010) 464:1367-70. doi: 10.1038/nature08900

93. Price AE, Liang HE, Sullivan BM, Reinhardt RL, Eisley CJ, Erle DJ, et al. Systemically dispersed innate IL-13-expressing cells in type 2 immunity. Proc Natl Acad Sci USA. (2010) 107:11489-94. doi: 10.1073/pnas.1003988107

94. Halim TY, Krauss RH, Sun AC, Takei F. Lung natural helper cells are a critical source of Th2 cell-type cytokines in protease allergen-induced airway inflammation. Immunity. (2012) 36:451-63. doi: 10.1016/j.immuni.2011.12.020

95. Kim BS, Siracusa MC, Saenz SA, Noti M, Monticelli LA, Sonnenberg GF, et al. TSLP elicits IL-33-independent innate lymphoid cell responses to promote skin inflammation. Sci Transl Med. (2013) 5:170ra116. doi: $10.1126 /$ scitranslmed.3005374

96. Spits H, Artis D, Colonna M, Diefenbach A, Di Santo JP, Eberl G, et al. Innate lymphoid cells-a proposal for uniform nomenclature. Nat Rev Immunol. (2013) 13:145-9. doi: 10.1038/nri3365

97. Vivier E, Artis D, Colonna M, Diefenbach A, Di Santo JP, Eberl G, et al. Innate lymphoid cells: 10 years on. Cell. (2018) 174:1054-66. doi: 10.1016/j.cell.2018.07.017

98. Bouchery T, Kyle R, Camberis M, Shepherd A, Filbey K, Smith A, et al. ILC2s and T cells cooperate to ensure maintenance of M2 macrophages for lung immunity against hookworms. Nat Commun. (2015) 6:6970. doi: $10.1038 /$ ncomms7970

99. Nadjsombati MS, McGinty JW, Lyons-Cohen MR, Jaffe JB, DiPeso L, Schneider C, et al. Detection of succinate by intestinal tuft cells 
triggers a type 2 innate immune circuit. Immunity. (2018) 49:33-41 e37. doi: 10.1016/j.immuni.2018.06.016

100. Schneider C, O'Leary CE, von Moltke J, Liang HE, Ang QY, Turnbaugh PJ, et al. A metabolite-triggered tuft cell-ILC2 circuit drives small intestinal remodeling. Cell. (2018) 174:271-84 e214. doi: 10.1016/j.cell.2018.05.014

101. Biton M, Haber AL, Rogel N, Burgin G, Beyaz S, Schnell A, et al. T helper cell cytokines modulate intestinal stem cell renewal and differentiation. Cell. (2018) 175:1307-20 e1322. doi: 10.1016/j.cell.2018.10.008

102. Haber AL, Biton M, Rogel N, Herbst RH, Shekhar K, Smillie C, et al. A singlecell survey of the small intestinal epithelium. Nature. (2017) 551:333-9. doi: $10.1038 /$ nature 24489

103. Nussbaum JC, Van Dyken SJ, von Moltke J, Cheng LE, Mohapatra A, Molofsky AB, et al. Type 2 innate lymphoid cells control eosinophil homeostasis. Nature. (2013) 502:245-8. doi: 10.1038/nature12526

104. Dent LA, Daly CM, Mayrhofer G, Zimmerman T, Hallett A, Bignold LP, et al. Interleukin-5 transgenic mice show enhanced resistance to primary infections with Nippostrongylus brasiliensis but not primary infections with Toxocara canis. Infect Immun. (1999) 67:989-93. doi: 10.1128/IAI.67.2.989-993.1999

105. Turner JE, Morrison PJ, Wilhelm C, Wilson M, Ahlfors H, Renauld JC, et al. IL-9-mediated survival of type 2 innate lymphoid cells promotes damage control in helminth-induced lung inflammation. J Exp Med. (2013) 210:2951-65. doi: 10.1084/jem.20130071

106. Wilhelm C, Hirota K, Stieglitz B, Van Snick J, Tolaini M, Lahl K, et al. An IL-9 fate reporter demonstrates the induction of an innate IL-9 response in lung inflammation. Nat Immunol. (2011) 12:1071-7. doi: 10.1038/ni.2133

107. Zaiss DMW, Gause WC, Osborne LC, Artis D. Emerging functions of amphiregulin in orchestrating immunity, inflammation, and tissue repair. Immunity. (2015) 42:216-26. doi: 10.1016/j.immuni.2015.01.020

108. Monticelli LA, Sonnenberg GF, Abt MC, Alenghat T, Ziegler CG, Doering TA, et al. Innate lymphoid cells promote lung-tissue homeostasis after infection with influenza virus. Nat Immunol. (2011) 12:1045-54. doi: 10.1038/ni.2131

109. Monticelli LA, Osborne LC, Noti M, Tran SV, Zaiss DM, Artis D. IL33 promotes an innate immune pathway of intestinal tissue protection dependent on amphiregulin-EGFR interactions. Proc Natl Acad Sci USA. (2015) 112:10762-7. doi: 10.1073/pnas.1509070112

110. Salimi M, Barlow JL, Saunders SP, Xue L, Gutowska-Owsiak D, Wang X, et al. A role for IL-25 and IL-33-driven type- 2 innate lymphoid cells in atopic dermatitis. J Exp Med. (2013) 210:2939-50. doi: 10.1084/jem.20130351

111. Ghaedi M, Shen ZY, Orangi M, Martinez-Gonzalez I, Wei L, Lu X, et al. Single-cell analysis of RORalpha tracer mouse lung reveals ILC progenitors and effector ILC2 subsets. J Exp Med. (2020) 217:jem.20182293. doi: $10.1084 /$ jem. 20182293

112. Barlow JL, Peel S, Fox J, Panova V, Hardman CS, Camelo A, et al. IL-33 is more potent than IL-25 in provoking IL-13-producing nuocytes. (type 2 innate lymphoid cells) and airway contraction. J Allergy Clin Immunol. (2013) 132:933-41. doi: 10.1016/j.jaci.2013.05.012

113. Chu DK, Llop-Guevara A, Walker TD, Flader K, Goncharova S, Boudreau JE, et al. IL-33, but not thymic stromal lymphopoietin or IL-25, is central to mite and peanut allergic sensitization. J Aller Clin Immunol. (2013) 131:187-200 e181. doi: 10.1016/j.jaci.2012.08.002

114. Saenz SA, Siracusa MC, Monticelli LA, Ziegler CG, Kim BS, Brestoff JR, et al. IL-25 simultaneously elicits distinct populations of innate lymphoid cells and multipotent progenitor type 2. (MPPtype2) cells. J Exp Med. (2013) 210:1823-37. doi: 10.1084/jem.20122332

115. Bjorklund AK, Forkel M, Picelli S, Konya V, Theorell J, Friberg D, et al. The heterogeneity of human $\mathrm{CD} 127(+)$ innate lymphoid cells revealed by singlecell RNA sequencing. Nat Immunol. (2016) 17:451-60. doi: 10.1038/ni.3368

116. Van Dyken SJ, Nussbaum JC, Lee J, Molofsky AB, Liang HE, Pollack JL, et al. A tissue checkpoint regulates type 2 immunity. Nat Immunol. (2016) 17:1381-7. doi: 10.1038/ni.3582

117. Wallrapp A, Riesenfeld SJ, Burkett PR, Abdulnour RE, Nyman J, Dionne $\mathrm{D}$, et al. The neuropeptide NMU amplifies ILC2-driven allergic lung inflammation. Nature. (2017) 549:351-6. doi: 10.1038/nature24029

118. Huang Y, Guo L, Qiu J, Chen X, Hu-Li J, Siebenlist U, et al. IL-25-responsive, lineage-negative KLRG1(hi) cells are multipotential 'inflammatory' type 2 innate lymphoid cells. Nat Immunol. (2015) 16:161-9. doi: 10.1038/ni.3078
119. Saenz SA, Siracusa MC, Perrigoue JG, Spencer SP, Urban JFJr, Tocker JE, et al. IL25 elicits a multipotent progenitor cell population that promotes $\mathrm{T}(\mathrm{H}) 2$ cytokine responses. Nature. (2010) 464:1362-6. doi: 10.1038/nature 08901

120. Miller MM, Patel PS, Bao K, Danhorn T, O'Connor BP, Reinhardt RL. BATF acts as an essential regulator of IL-25-responsive migratory ILC2 cell fate and function. Sci Immunol. (2020) 5:eaay3994. doi: 10.1126/sciimmunol.aay3994

121. Bando JK, Nussbaum JC, Liang HE, Locksley RM. Type 2 innate lymphoid cells constitutively express arginase-I in the naive and inflamed lung. J Leukoc Biol. (2013) 94:877-84. doi: 10.1189/jlb.0213084

122. Bando JK, Liang HE, Locksley RM. Identification and distribution of developing innate lymphoid cells in the fetal mouse intestine. Nat Immunol. (2015) 16:153-60. doi: 10.1038/ni.3057

123. Monticelli LA, Buck MD, Flamar AL, Saenz SA, Tait Wojno ED, Yudanin $\mathrm{NA}$, et al. Arginase 1 is an innate lymphoid-cell-intrinsic metabolic checkpoint controlling type 2 inflammation. Nat Immunol. (2016) 17:65665. doi: 10.1038/ni.3421

124. Mohrs M, Shinkai K, Mohrs K, Locksley RM. Analysis of type 2 immunity in vivo with a bicistronic IL-4 reporter. Immunity. (2001) 15:303-11. doi: 10.1016/S1074-7613(01)00186-8

125. Mohrs K, Wakil AE, Killeen N, Locksley RM, Mohrs M. A two-step process for cytokine production revealed by IL-4 dual-reporter mice. Immunity. (2005) 23:419-29. doi: 10.1016/j.immuni.2005.09.006

126. Yasuda K, Muto T, Kawagoe T, Matsumoto M, Sasaki Y, Matsushita K, et al. Contribution of IL-33-activated type II innate lymphoid cells to pulmonary eosinophilia in intestinal nematode-infected mice. Proc Natl Acad Sci USA. (2012) 109:3451-6. doi: 10.1073/pnas.1201042109

127. Hung LY, Lewkowich IP, Dawson LA, Downey J, Yang Y, Smith DE, et al. IL-33 drives biphasic IL-13 production for noncanonical Type 2 immunity against hookworms. Proc Natl Acad Sci USA. (2013) 110:282-7. doi: 10.1073/pnas.1206587110

128. Gracz AD, Samsa LA, Fordham MJ, Trotier DC, Zwarycz B, Lo YH, et al. Sox4 promotes Atoh1-independent intestinal secretory differentiation toward tuft and enteroendocrine fates. Gastroenterology. (2018) 155:1508-23 e1510. doi: 10.1053/j.gastro.2018.07.023

129. Pelly VS, Kannan Y, Coomes SM, Entwistle LJ, Ruckerl D, Seddon B, et al. IL4-producing ILC2s are required for the differentiation of TH2 cells following Heligmosomoides polygyrus infection. Mucosal Immunol. (2016) 9:1407-17. doi: 10.1038/mi.2016.4

130. Zhang K, Xu X, Pasha MA, Siebel CW, Costello A, Haczku A, et al. Cutting edge: notch signaling promotes the plasticity of group-2 innate lymphoid cells. J Immunol. (2017) 198:1798-803. doi: 10.4049/jimmunol.1601421

131. Ricardo-Gonzalez RR, Van Dyken SJ, Schneider C, Lee J, Nussbaum JC, Liang HE, et al. Tissue signals imprint ILC2 identity with anticipatory function. Nat Immunol. (2018) 19:1093-9. doi: 10.1038/s41590-018-0201-4

132. Antignano F, Braam M, Hughes MR, Chenery AL, Burrows K, Gold MJ, et al. G9a regulates group 2 innate lymphoid cell development by repressing the group 3 innate lymphoid cell program. J Exp Med. (2016) 213:1153-62. doi: 10.1084/jem.20151646

133. Bernink JH, Ohne Y, Teunissen MBM, Wang J, Wu J, Krabbendam L, et al. c-Kit-positive ILC2s exhibit an ILC3-like signature that may contribute to IL-17-mediated pathologies. Nat Immunol. (2019) 20:9921003. doi: 10.1038/s41590-019-0423-0

134. Hochdorfer T, Winkler C, Pardali K, Mjosberg J. Expression of cKit discriminates between two functionally distinct subsets of human type 2 innate lymphoid cells. Eur J Immunol. (2019) 49:884-93. doi: $10.1002 /$ eji.201848006

135. Schneider C, Lee J, Koga S, Ricardo-Gonzalez RR, Nussbaum JC, Smith LK, et al. Tissue-resident group 2 innate lymphoid cells differentiate by layered ontogeny and in situ perinatal priming. Immunity. (2019) 50:1425-38 e1425. doi: 10.1016/j.immuni.2019.04.019

136. Ricardo-Gonzalez RR, Schneider C, Liao C, Lee J, Liang HE, Locksley RM. Tissue-specific pathways extrude activated ILC2s to disseminate type 2 immunity. J Exp Med. (2020) 217:jem.20191172. doi: 10.1084/jem.201 91172

137. Gasteiger G, Fan X, Dikiy S, Lee SY, Rudensky AY. Tissue residency of innate lymphoid cells in lymphoid and nonlymphoid organs. Science. (2015) 350:981-5. doi: 10.1126/science.aac9593 
138. O'Sullivan TE, Rapp M, Fan X, Weizman OE, Bhardwaj P, Adams $\mathrm{NM}$, et al. Adipose-resident group 1 innate lymphoid cells promote obesity-associated insulin resistance. Immunity. (2016) 45:428-41. doi: 10.1016/j.immuni.2016.06.016

139. Bal SM, Golebski K, Spits H. Plasticity of innate lymphoid cell subsets. Nat Rev Immunol. (2020). doi: 10.1038/s41577-020-0282-9. [Epub ahead of print].

140. Entwistle LJ, Gregory LG, Oliver RA, Branchett WJ, Puttur F, Lloyd CM. Pulmonary group 2 innate lymphoid cell phenotype is context specific: determining the effect of strain, location, and stimuli. Front Immunol. (2019) 10:3114. doi: 10.3389/fimmu.2019.03114

141. de Kleer IM, Kool M, de Bruijn MJ, Willart M, van Moorleghem J, Schuijs MJ, et al. Perinatal activation of the interleukin-33 pathway promotes type 2 immunity in the developing lung. Immunity. (2016) 45:1285-98. doi: 10.1016/j.immuni.2016.10.031

142. Saluzzo S, Gorki AD, Rana BMJ, Martins R, Scanlon S, Starkl P, et al. Firstbreath-induced type 2 pathways shape the lung immune environment. Cell Rep. (2017) 18:1893-905. doi: 10.1016/j.celrep.2017.01.071

143. Steer CA, Martinez-Gonzalez I, Ghaedi M, Allinger P, Matha L, Takei F. Group 2 innate lymphoid cell activation in the neonatal lung drives type 2 immunity and allergen sensitization. J Aller Clin Immunol. (2017) 140:593-5 e593. doi: 10.1016/j.jaci.2016.12.984

144. Huang Y, Mao K, Chen X, Sun MA, Kawabe T, Li W, et al. S1P-dependent interorgan trafficking of group 2 innate lymphoid cells supports host defense. Science. (2018) 359:114-9. doi: 10.1126/science.aam5809

145. Campbell L, Hepworth MR, Whittingham-Dowd J, Thompson S, Bancroft AJ, Hayes KS, et al. ILC2s mediate systemic innate protection by priming mucus production at distal mucosal sites. J Exp Med. (2019) 216:2714-23. doi: 10.1084/jem.20180610

146. Lim AI, Li Y, Lopez-Lastra S, Stadhouders R, Paul F, Casrouge A, et al. Systemic human ILC precursors provide a substrate for tissue ILC differentiation. Cell. (2017) 168:1086-100 e1010. doi: 10.1016/j.cell.2017.02.021

147. Flamar AL, Klose CSN, Moeller JB, Mahlakoiv T, Bessman NJ, Zhang W, et al. Interleukin-33 induces the enzyme tryptophan hydroxylase 1 to promote inflammatory group 2 innate lymphoid cell-mediated immunity. Immunity. (2020) 52:606-19 e606. doi: 10.1016/j.immuni.2020.02.009

148. Puttur F, Denney L, Gregory LG, Vuononvirta J, Oliver R, Entwistle LJ, et al. Pulmonary environmental cues drive group 2 innate lymphoid cell dynamics in mice and humans. Sci Immunol. (2019) 4:eaav7638. doi: 10.1126/sciimmunol.aav7638

149. Hoyler T, Klose CS, Souabni A, Turqueti-Neves A, Pfeifer D, Rawlins EL, et al. The transcription factor GATA-3 controls cell fate and maintenance of type 2 innate lymphoid cells. Immunity. (2012) 37:634-48. doi: 10.1016/j.immuni.2012.06.020

150. Kim CH, Hashimoto-Hill S, Kim M. Migration and tissue tropism of innate lymphoid cells. Trends Immunol. (2016) 37:68-79. doi: 10.1016/j.it.2015.11.003

151. Stier MT, Zhang J, Goleniewska K, Cephus JY, Rusznak M, Wu L, et al. IL-33 promotes the egress of group 2 innate lymphoid cells from the bone marrow. J Exp Med. (2018) 215:263-81. doi: 10.1084/jem.201 70449

152. Walker JA, Clark PA, Crisp A, Barlow JL, Szeto A, Ferreira ACF, et al. Polychromic reporter mice reveal unappreciated innate lymphoid cell progenitor heterogeneity and elusive ILC3 progenitors in bone marrow. Immunity. (2019) 51:104-18 e107. doi: 10.1016/j.immuni.2019.05.002

153. Gold DR, Acevedo-Garcia D. Immigration to the United States and acculturation as risk factors for asthma and allergy. $J$ Allergy Clin Immunol. (2005) 116:38-41. doi: 10.1016/j.jaci.2005. 04.033

154. Flohr C, Quinnell RJ, Britton J. Do helminth parasites protect against atopy and allergic disease? Clin Exp Allergy. (2009) 39:20-32. doi: $10.1111 / \mathrm{j} .1365-2222.2008 .03134 . x$

155. McSorley HJ, Maizels RM. Helminth infections and host immune regulation. Clin Microbiol Rev. (2012) 25:585-608. doi: 10.1128/CMR. 05040-11

Conflict of Interest: The authors declare that the research was conducted in the absence of any commercial or financial relationships that could be construed as a potential conflict of interest.

Copyright (c) 2020 Miller and Reinhardt. This is an open-access article distributed under the terms of the Creative Commons Attribution License (CC BY). The use, distribution or reproduction in other forums is permitted, provided the original author(s) and the copyright owner(s) are credited and that the original publication in this journal is cited, in accordance with accepted academic practice. No use, distribution or reproduction is permitted which does not comply with these terms. 